\title{
La ciudad de Barcelona en la guerra contra Felipe IV: el Consell de Cent, más que un gobierno municipal
}

\author{
Núria Florensa I SOler *
}

\begin{abstract}
RESUMEN
ABSTRACT

La constitución del gobierno municipal

The constitution of the municipal barcelonés - el Consell de Cent-se inició en el siglo xvill y perduró hasta su abolición en 1714. El Consell de

Cent ejerció actividades más allá de las estrictamente locales. A lo largo de su historia, tuvo gran importancia en diversos ámbitos de la política y de la

economía de Cataluña. Hay que destacar su papel decisivo al inicio de la Guerra de Separación (en 1640).

Barcelona fue concentrando atribuciones y ejecutando decisiones: politicas, judiciales, económicas, militares..., convirtiéndose en el bastión de la guerra contra Castilla, que simbolizaba el absolutismo de

Felipe $\mathrm{IV}$ y de sus ministros, en especial del conde de Olivares y del protonotario Villanueva. Durante su reinado, el Consell de Cent sufrió constantes presiones económicas, militares y agravios varios. Tambiên governement of Barcelona - The Consell de Cent- began in the XIII century and lasted till its abolition in 1714. The Consell de Cent exercised activities beyond the strictly local ones. All through its history, it had a great importance both in politics and economics in Catalonia. Its decisive role at the beginning of the Separation war (in 1640) should be pointed out. Barcelona started concentrating authority and executing decisions: political, judiciary, economic, military. It became the bastion of the war against Castile which symbolized the absolutism of Philip IV and his ministers especialy count Olivares and protonotary Villanueva. During his reing, the Consell de Cent suffered constant economic and military preseure and injustice: also the municipal
\end{abstract}

* Centre d'Estudis d'Historia Moderna Pierre Vilar. 
se conculcaron las constituciones

municipales. Los consellers y los diputats formaron un bloque contra la Corona, esta unión fue esencial para el éxito de la revuelta catalana, y la fase inicial de la guerra. Cataluña y

Castilla mantuvieron una guerra intelectual y psicológica ("La Guerra de tinta") para autojustificarse y atraer partidarios a sus intereses. constitutions were infringed. The councillors and the representatives formed a block against the Crown and his meeting up was vital for the success of the catalan revolt in the first moments of the war. Catalonia and Castile kept an intellectual and psychological war ("Ink war") to justify on themselvs and attract supporters fo their interests.

La guerra de Separación de la Monarquía hispánica es uno de los temas más trabajados en la historiografía catalana, pero afortunadamente el avance de la ciencia histórica aporta nuevos datos que perfilan más esta cuestión. Con el presente artículo pretendemos enfocar aquella etapa en cuatro vertientes.

Primero, trato de enfatizar la importancia de Barcelona, entendiendo la formación y evolución del Consell de Cent como un ejemplo que siguieron las poblaciones catalanas. Segundo, analizo los cambios significativos del Consell de Cent durante el siglo XVII. Tercero, me centro en el papel directivo de Barcelona en la guerra que entabló Cataluña contra Felipe IV. Finalmente, apunto el papel pionero del Consell de Cent en la campaña publicistica a favor de la guerra.

Barcelona hizo grandes aportaciones económicas a los reyes de la Corona de Aragón y en agradecimiento éstos le hicieron muchas concesiones de privilegios municipales. La ciudad se convirtió en la más importante de Cataluña por su auge político y económico. En época medieval y moderna fue cuestionada su capitalidad por otras ciudades, sin por ello dejar de reconocer el papel protagonista y directivo asumido por Barcelona en diversos acontecimientos que implicaban al conjunto de Cataluña y su creciente responsabilidad y ascendiente político respecto de otras instituciones. De modo progresivo, la Ciudad Condal fue representando a los catalanes y en caso de necesidad, conflictos, peligro, etc. las poblaciones catalanas le escribian solicitando su ayuda. En los escritos coetáneos la consideraban "cabeza del Reino y refugio de toda Cataluña» '.

\footnotetext{
Bruniouer, Esteve Gilabert, Ceremonial dels magnifics consellers y regiment de la ciutat de Barcelona (Rúbriques, obra de 1614), 5 vols., Barcelona, 1912-1916, vol. I, págs. 193-194, 211, vol. IV, pág. 338. Carreras I CANDI, Francesc, Hegemonia de Barcelona en Cataluña durante el siglo $\times v$. Barcelona, 1898.
} 
Los origenes del Consell de Cent hay que buscarlos en los inicios del siglo XII, cuando los vecinos de Barcelona formaron la universidad de los prohoms o de los ciudadanos. Estos no sólo representaban a la comunidad, sino que participaban activamente en la defensa de los intereses generales que les afectaban, y lo hacían delante del rey, de sus oficiales o de quien convenía. Al transcurrir el tiempo y aumentar la población, no pudieron hacerse los consejos abiertos; por ello, se delegó en un consejo más reducido que se convertiria en el Consell de Cent. Inicialmente, las personas eran escogidas de forma directa, por aclamación, por voto familiar, etc. Posteriormente, a través de mecanismos indirectos: por cooptación, por compromisarios y finalmente por insaculación ?

Jaime I inició la constitución del gobierno municipal barcelonés, siguiendo el modelo del que habia formado después de la conquista de $\mathrm{Va}$ lencia ${ }^{3}$. En el año 1249 le concedió a Barcelona el privilegio de elegir a sus representantes, que se renovaban anualmente y que tenían la facultad de escoger -cooptación - a quien quisieran para el Consell. De esta forma, se consolidó un régimen municipal oligárquico. En 1274, Jaime 1 concedió un nuevo privilegio y quedó constituida definitivamente la organización municipal: 5 consellers ejecutivos escogidos el día de San Andrés ${ }^{4}$ para ejercer un año el cargo: 100 jurados consultivos ${ }^{5}$, que a final de año nombraban una comisión de 12 personas -compromisarios-encargadas de elegir a los nuevos consellers.

En aquel tiempo, el veguer de Barcelona era la máxima autoridad real en la ciudad. Una de sus funciones era convocar al Consejo municipal, lo que entró en competencia con las atribuciones de los consellers, que finalmente resolvieron el contencioso a su favor. Los consellers poco a poco dejaron de ser asesores de los oficiales reales, adquiriendo funciones de decisión y actividades ejecutivas. Los oficiales reales, el veguer y el batlle, fueron cediendo potestades a favor de la estructura municipal, y sus cargos se vincularon y pasaron a depender -en parte- de los consellers ${ }^{6}$.

\footnotetext{
La insaculación era un procedimiento basado en una selección previa de personas de cada estamento cuyos nombres se introducian en una bolsa y luego se extraían al azar.

3 Biblioteca de Catalunya (en adelante, BC). Fuliet Bonscoms (en adelante. F.B.). Font 1 Rıus, José M. Jaume l i la municipalitat de Barcelona, Barcelona, 1977, págs. 31-32, 46-47; y Estudis sobre els drets i institucions locals en la Catalunya medieval, Barcelona, 1985, pág. 639.

Día de San Andrés: 30 de noviembre, comienzo del año consular. El Consell de Cent iniciaba el cómputo de tiempo municipal en esta fecha con la extracción de los nuevos consellers.

El total de jurados del Consell de Cent evolucionó con los años. Osciló de 249 a 128 escaños, repartidos entre los cuatro estamentos de la ciudad: ciudadanos, mercaderes, artistas y menestrales. Font RIus, J.M., Jaume /..., págs. 53-54.
} 
Las disposiciones reales potenciaron el cargo de conseller y la transformación del gobierno municipal en una institución autónoma?

En 1283, Pedro II concedió a Barcelona el privilegio «Recognoverunt proceres" que otorgaba a la ciudad la libertad de escoger a sus consellers y oficiales, además de establecer la renuncia real a cobrar los impuestos municipales. Con esta autonomía económica Barcelona pudo aumentar y consolidar su libertad política. Así mismo, el veguer y el batlle juraban delante de los consellers, que se comprometían a dejarse aconsejar por ellos y que respetarian los privilegios de la ciudad ${ }^{8}$.

Barcelona siguió la misma evolución que las ciudades europeas de la época. Alcanzó gran importancia política y económica en la Corona de Aragón: gran centro comercial del Mediterráneo y residencia de los condes primero, y de los reyes después. Durante mucho tiempo, la ciudad tuvo una estrecha vinculación con la Corona, que como hemos destacado la constituyó en capital de Cataluña, al tiempo que obtenia su apoyo para la expansión mediterránea. Por todo ello, progresivamente Barcelona consiguió unos privilegios especiales superiores a los de otras ciudades. Paulatinamente, en la organización municipal se modificó la rígida tendencia oligárquica, debido a diversos cambios, entre los que hay que destacar la disminución del estamento de los mercaderes, la mayor participación de los menestrales, etc. Pero los grupos hegemónicos ${ }^{9}$ - formados por clanes familiares - se opusieron sistemáticamente a las reformas para no perder su situación privilegiada, por lo que las revueltas urbanas fueron frecuentes a lo largo de la historia del municipio ${ }^{10}$.

Fernando II realizó una reforma general de la que hay que señalar la insaculación y la aceptación de un militar como conseller ${ }^{11}$. Admitidos los caballeros en el gobierno municipal en 1510, los ciudadanos honrados conseguirían equipararse a la categoría de caballeros y por privilegio real

Font RIUs, J.M., Jaume I ..., págs. 54-55.

8 Bruniquer, E.G., Ceremonial dels magnifics consellers ..., vol. 1, pág. 79. BC, FB-255, pág 9. BATLle I GaLlART, Carme, «El govern municipal a la Baixa Edat Mitjana», El govern de les ciutats catalanes, Barcelona, 1985, págs. 61-68, en concreto la pág. 68.

9 AMELANG, James S., La formación de una clase dirigente: Barcelona 1490-1714, Barcelona, 1986. PaLOS, Joan Lluís, Catalunya a I'Imperi dels Áustria. La pràctica de govern (segles XVI $i$ XVII), Lleida, 1994.

10 VICENS Vives, Jaume. Ferran II i la ciutat de Barcelona 1479-1516, 3 vols., Barcelona, 1936-37. CARRÉRE, Claude, Barcelone, centre économique à l'époque des difficultés 1380-1462, 2 vols., Paris-La Haya, 1967 (edición catalana de 1977-78). Batlle GallaRt, Carme, La crisis socialy económica de Barcelona a mediados del siglo xv, 2 vols., Barcelona, 1973. Del TrEPPo, Mario, Els mercaders catalans i l'expansió de la corona catalano-aragonesa al segle XV. Barcelona, 1976.

Vid. VICENS VIVES, J., Ferran 11 .... 
gozarían de privilegio militar. En el año 1493 el Consell de Cent quedó compuesto por 144 jurados, distribuidos en la siguiente proporción: 48 ciudadanos honrados, 32 mercaderes, 32 artistas y 32 menestrales. La Conselleria, el órgano ejecutivo, estuvo formada por cinco consellers: 3 ciudadanos, 1 mercader y 1 artista o menestral que se alternaban el cargo anualmente. Los consellers procuraron mantener los privilegios que tenía Barcelona, consiguiendo reiteradamente de los monarcas su confirmación: en 1519 de la reina Juana y su hijo Carlos I, en el año 1547 de Felipe II, en 1615 de Felipe III, etc. Así se estableció de manera casi definitiva el funcionamiento del Consell de Cent hasta su desaparición en 1714.

Sobre esta base, durante el siglo XVII se produjeron tres cambios significativos en el gobierno municipal. En primer lugar la admisión de la nobleza el año 1621. Finalizada la guerra civil catalana del siglo XV, muchos nobles y caballeros abandonaron las zonas rurales y marcharon a vivir a las ciudades, donde tenían más comodidades. Al establecerse en Barcelona, se interesaron por los asuntos de la ciudad y quisieron participar en su gobierno, con la oposición de los que ostentaban el poder municipal ${ }^{12}$. A pesar de los impedimentos interpuestos por los ciudadanos honrados y algunos caballeros, la nobleza procuró insistentemente entrar en el gobierno de la ciudad hasta que lo consiguió. El primer estamento de la ciudad aducía que los nobles tenian su baluarte en la Generalitat y que, al no estar representados en el Consell de Cent, éste podía hacer de mediador entre la nobleza, la Corona y los diputats. En las Cortes de 1599, la nobleza consiguió de Felipe III que la decisión de su inclusión fuera tomada por los municipios. Este contencioso fue un motivo más de disputa y una causa más de dificultad para que pudieran imprimirse las constituciones. Finalmente, la nobleza obtuvo la aceptación de los estamentos de la ciudad y en 1621 entró en el gobierno de Barcelona ${ }^{13}$.

Se podian insacular cuatro nobles en cada bolsa de conseller primero, segundo y tercero, pero sin que aumentase el total de los miembros. Durante siglos, los ciudadanos honrados tuvieron el control de Barcelona. Poco a poco, el grupo tuvo que ampliarse debido a las reivindicaciones de otros colectivos como los caballeros, la nobleza titulada y los doctores en derecho y medicina. Este conjunto privilegiado asi aumentado mantuvo la hegemonía urbana e impuso su poder como primer estamento de la ciudad sobre mercaderes, artistas y menestrales.

\footnotetext{
12 ELLiOTT, John $H$., "Una aristocràcia provincial: la classe dominant catalana en els segles XV i xvil”: L Ávenç, núm. 40, 1981, págs. 26-35, en concreto págs. 29-30.

13 BC, FB-255, págs. 21, 49-51.
} 
La segunda novedad relevante fue la incorporación fija de un conseller menestral (el conseller sexto), que tuvo lugar en el año 1641 durante la guerra de Separación ${ }^{14}$. Celosos de esta prerrogativa y dentro del fenómeno de la cascada del menosprecio, los mismos menestrales establecían una jerarquía socio-profesional e impedían el acceso al municipio de los oficios considerados viles y de ciertas cofradias. En 1626, celebrándose Cortes en Barcelona, el Consell de Cent acordó solicitar al rey que le concediera el privilegio de prohibir el acceso al cargo de conseller a los que ejercieran los oficios de carniceros, corredores de “coll» (vendedores de bienes), corredores de bestias, músicos, taberneros, hostaleros, revendedores y panaderos, además de solicitar otras disposiciones muy duras para la formación de las cofradias, aunque las medidas no fueron aprobadas al no concluirse las Cortes, ya que, como es bien sabido, Felipe IV abandonó Barcelona precipitadamente ${ }^{15}$.

La ocasión de modificar la composición de la Consellería se presentaría en pleno proceso revolucionario. Cada año en el Consell de Cent se extraían los cinco miembros ejecutivos de la Conselleria y se renovaba la mitad del plenario: 72 jurados permanecían, y otros 72 eran sustituidos por otros nuevos. En noviembre de 1640, al inicio de la guerra de Separación, los dirigentes catalanes necesitaban asegurar a las personas claves en las funciones importantes. Los líderes catalanes más opuestos al absolutismo de la Monarquía hispánica serían los que ocuparan los cargos más elevados de las instituciones de Cataluña en los momentos más conflictivos.

En la insaculación municipal de 1640, el pacto sustituyó al azar. Por ello, se forzó la extracción del conseller en cap (el primero) para que fuese nombrado el doctor Joan Pere Fontanella, eminente jurista que gozaba de prestigio europeo ${ }^{16}$.

$Y$ también se vulneraron los privilegios reales: se aumentó el número de jurados en el Consell de Cent, que pasó de 144 a 216 miembros, ya

14 Florensa I SOLER, Núria, “El bienni de transició: 1640-1641. Conftictes socials a Barcelona: el conseller sisè menestral i la revolució urbana»: Carlos Martinez Shaw (ed.), Congrés História moderna, història en construcción, Editorial Milenio, Lleida, 1999, vol. II, pàgs. 497-511.

15 lbidem.

16 Joan Pere Fontanella (1576-1649) fue un eminente jurista que gozó de gran prestigio en Cataluña y en Europa. Publicó diversos libros con recopilaciones jurídicas. Sostuvo diversos contenciosos en favor del Consell de Cent y de la Generalitat en defensa de las Constituciones de Cataluña, por lo que se entrentó en diversas ocasiones con la Corona.(Diccionari d'história de Catalunya, Barcelona, 1993). FLORENSA I SOLER, Núria, "La insaculació pactada. Barcelona 1640": Actes Tercer Congrés d'Història Moderna de Catalunya, vol. I, Barcelona, 1993, págs. 447-455. 
que los 72 jurados que tenían que ser sustituidos permanecieron en él. Algunos eran consellers y jurados claves que pertenecian a la Junta de Guerra municipal, participaban en las decisiones en la Generalitat y además pertenecían a una Junta Secreta. Eran hombres de confianza de los revolucionarios y por lo tanto no podía prescindirse de ellos. Como por ejemplo Francesc Joan Vergós, que era de la Junta Secreta y actuaba de acuerdo con Pau Claris, además de formar parte del Consejo de Guerra y ser un jurado muy influyente en el propio Consell de Cent ${ }^{17}$. Así, incrementada la representación por necesidad, para legitimar y para vincular decisiones, al final la medida sirvió para establecer unas bases más populares al ampliarse los miembros del pleno.

Del mismo modo, debido a la situación revolucionaria del bienio de 1640-1641, los artistas y menestrales vieron el momento propicio para plantear algunas reivindicaciones. Los estamentos populares, en efecto, estaban descontentos de su representación en el gobierno de la ciudad; en especial los artistas y menestrales no querian alternarse anualmente el cargo de conseller quinto. Así, al replantearse en noviembre de 1641 la insaculación para el año consular de 1642 unos y otros vieron el momento oportuno para radicalizar sus reivindicaciones. Se hizo una elección excepcional que sólo fue válida para aquélla ocasión. La finalidad de los estamentos privilegiados era mantener su situación hegemónica dentro de la estructura municipal. Por lo tanto, procuraron hacer los mínimos cambios y se vieron favorecidos por las disputas entre menestrales, que tenían multiplicidad de intereses y rivalidades entre ellos. Habia cofradias menestrales cuyos miembros podian ser jurados del Consell de Cent, pero no consellers en la Conselleria. Y a la inversa, los miembros de otras cofradias menestrales podian formar parte de la Conselleria, pero no tenían acceso para ser jurados en el pleno. Existía situación similar para ejercer los otros cargos municipales: no todas las cofradías menestrales podían ejercer de oficiales de la ciudad. Así pues, algunas cofradias estaban excluidas del gobierno municipal y no todas tenían la misma representación.

Finalmente no se hicieron cambios: se mantuvieron los privilegios adquiridos de los gremios, colegios y cofradías de artistas y menestrales que ya estaban representados en el Consell de Cent y en las bolsas de conseller. Las capas populares habían luchado entre sí, unas para conservar

17 F.J. Vergós hubiera cesado el 30 de noviembre de 1640. AHCB, Deliberacions, 1641, f. 3v. TORME I LIORI, Alberto, Miscelláneos históricos y políticos sobre la guerra de Cataluña desde el año de 1639, (AHCB, Ms. A-51, págs. 134v.-135). PI Y ARIMON, A.A., Barcelona, antigua y moderna, tomo II, Barcelona, 1854, pág. 638. 
sus prerrogativas y otras para conseguirlas. De esta manera impidieron un cambio estructural de la organización municipal que pudiera beneficiarlas y se mantuvo el «status» de los estamentos privilegiados. Éstos utilizaron la táctica dilatoria y aplazaron las concesiones, pero finalmente accedieron a aceptar un conseller menestral fijo en la Conselleria, que pasó así de 5 a 6 miembros en el año consular de 1642. La inclusión del conseller sexto menestral sirvió para llegar a un compromiso y apaciguar las otras reivindicaciones menestrales. Así pues, se lograba una reivindicación que había estado periódicamente presente en los momentos de conflictos locales, pero que también se utilizó en plena guerra ${ }^{18}$.

El tercer cambio en el Consell de Cent se produjo ya al finalizar la Guerra de Separación: la Corona se reservó el control real de las insaculaciones como consecuencia de su victoria. Después de la capitulación de Barcelona en 1652, Felipe IV propugnó una politica favorable de mantener el «status» jurídico e institucional de Cataluña, pero al mismo tiempo quiso asegurarse el control de la vida pública catalana ${ }^{19}$. Así, la Corona se reservó el derecho de otorgar la aquiescencia a las personas que la Generalitat y el Consell de Cent propusieran insacular para los cargos institucionales. De esta manera, Cataluña perdia la autonomía política que había ostentado. Hay que tener en cuenta el precedente ocurrido en el transcurso de la guerra de Separación, durante la cual los virreyes franceses habian manipulado las insaculaciones de los cargos del Consell de Cent, dejando excluidos a los desertores o desafectos ${ }^{20}$.

Felipe IV lo comunicó a Barcelona en estos términos y con estas justificaciones:

\begin{abstract}
"Assimismo me reservo durante mi voluntad, el hazer la insaculación de las personas que huvieren de concurrir, y tener los oficios de govierno de dicha Ciudad; para los quales, no han de poder ser admitidos, ni insaculados, sino los que yo nombrare, proponiendo la Ciudad en los tiempos que se suele hazer la insaculación las personas más a propósito; porque de ellas, o de otros, nombre yo las que me parecieren, las quales solo tengan derecho a estar en las Bolsas, y a concurrir a estos oficios, mientras yo no se lo prohibiere (...) este mismo derecho tengo en las otras ciudades de la
\end{abstract}

18 FloRensa I SOleR, N., “El bienni de transició...”, págs. 497-511.

19 Sanchez Marcos, Fernando, Cataluña y el gobierno central tras la Guerra de los Segadores (1652-1679), Barcelona, 1983, págs. 96-117; “El nuevo status de Barcelona tras su reincorporación a la monarquía hispánica en 1652": Homenaje al Dr. Dn. Juan Reglà Campistol, vol.I, València, 1975, págs. 597-609; “El autogobierno perdido en 1652: el control por Madrid de la vida política en Cataluña durante el virreinato de Don Juan de Austria (1653-1656)": Pedralbes, núm. 2, 1982, págs. 101-125.

20 SÁnCHez MARCOS, F., “El autogobierno perdido...”, pág. 104. 
Corona que con tanta paz se han conservado hasta aora (...) [las personas] me parecieran más a propósito para su mayor quietud y sossiego, y que con mayor zelo de la misma Ciudad la puedan governar» ${ }^{21}$.

Barcelona procuró por todos los medios recuperar sus antiguas prerrogativas en relación con las insaculaciones, haciendo numerosas gestiones, que finalmente resultaron infructuosas ${ }^{22}$. El control de las insaculaciones por parte de la Monarquía se convirtió en un mecanismo de represión de la disidencia política, en un elemento valioso para otorgar cargos y honores y, básicamente, como afirmaba el Consejo de Aragón, en un instrumento para "tener a raya a la ciudad de Barcelona" ${ }^{23}$. Era bien conocido que como capital de Cataluña tenía un peso específico indiscutible, había dirigido política y económicamente la Guerra de Separación y su representación en las Cortes era superior a la de otras ciudades: el conseller en cap de Barcelona presidia el braç reial ${ }^{24}$.

La Guerra de Separación (conocida popularmente como la guerra dels Segadors) se ha relacionado directamente con la presión fiscal y militar que ocasionó la Guerra de los Treinta Años (1618-1648) ${ }^{25} \mathrm{y}$, de manera más próxima, con la guerra contra Francia en $1635^{26}$. Como es bien sabido, el estallido próximo se produjo por las peculiares circunstancias bélicas que afectaron Cataluña entre 1639 y 1640 sobre todo a partir de la caida de Salses. Los oficiales reales tuvieron grandes dificultades en reclutar catalanes para luchar, por lo que en diversas ocasiones lo realizaron a la fuerza, provocando conflictos con las autoridades locales. Los consellers de Barcelona se resistian a facilitar las levas y se oponian si éstas se hacian por la fuerza, por ser contrarias a las Constituciones de Cataluña (como la

\footnotetext{
21 Dietari del Antich Consell Barceloni, vol. XVI, Barcelona, 1918, pág. 36, citado por SANCHEZ MARCOS, F., "El autogobierno perdido...", 1982, pág. 105

22 SAnChez MARCos. Fernando, "Los intentos de Barcelona en 1660-1661 de recuperar su status constitucional anterior a 1640": Cuadernos de Historia Moderna y Contemporánea, núm. 9, 1976, págs. 39-52.

${ }^{23}$ TORRAS ! Ribe, Josep M. ${ }^{\text {a }}$ "El control polític de les insaculacions del Consell de Cent de Barcelona (1652-1700)": Actes Tercer Congrés d'Historia Moderna de Catalunya, vol. I, Barcelona, 1993, págs. $457-468$

24 Sanchez Marcos, F., «El autogobierno perdido...", pág. 104. Flonensa I Soler, Núria, El Consell de Cent. Barcelona a la Guerra dels Segadors, Barcelona, 1996, págs. 232-235.

${ }_{25}$ SANABRE, José, La acción de Francia en Cataluña en la pugna por la hegemonía de Europa (1640-1659), Barcelona, 1956. RODENAS VILAR, Rafael, La politica europea de España durante la guerra de los Treinta Años (1624-1630), Madrid, 1967.

26 Echevaria Bacigalupe, Miguel Ángel, "Reformismo fiscal y resistencia institucional en torno a 1635": Actes Tercer Congrés d'História Moderna de Catalunya, vol. II. Barcelona, 1993, págs. 111-119. ZudaIRE HuARTE, Eulogio, "Cortes Catalanas. Comentarios a un informe del año 1635», Hispania, núm 68, 1957, págs. 395-423.
} 
Pragmática Princeps Namque). La invasión francesa del Rosellón en el año 1639 (réplica de la ofensiva hispánica de 1637) agudizó el problema del reclutamiento de soldados catalanes ${ }^{27}$.

Durante la campaña de Salses, para recuperar la fortaleza de manos francesas, las relaciones entre los catalanes y la Corte se hicieron muy tensas, generándose grandes diferencias, que llegaron a ser insalvables. Entre ellas cabe destacar el menosprecio hacia el honor de los catalanes, a quienes se consideró cobardes a causa de las deserciones - por otra parte, frecuentes en los ejércitos en aquella época-. Las deserciones fueron debidas a la fuerte lluvia, el viento, el frío y básicamente la peste, elementos que azotaron al ejército hispánico durante el sitio del castillo. Después de expulsar a los franceses, las autoridades catalanas recibieron órdenes estrictas de alojar al ejército real, motivo desencadenante de la guerra ${ }^{28}$.

Los alojamientos y los excesos de los soldados empujaron a la Generalitat a redactar diversos informes y memoriales de quejas y del mismo modo operó el Consell de Cent. El 4 de febrero de 1640, los consellers de Barcelona enviaron una carta al rey, la primera de una larga serie sobre los excesos de los soldados. Por privilegios reales, la ciudad estaba exenta de alojamientos, pero puntualmente recibia noticias de las poblaciones que los sufrían ${ }^{29}$, además de las informaciones que le transmitian los diputats. Los consellers hicieron las protestas necesarias a todas las instituciones (Rey, Consejo de Aragón, etc.) y a las personalidades de la Corte vinculadas con Cataluña.

A finales de febrero, el regente devolvió una escritura al Consell de Cent para que se suprimiera la palabra protesta y en su lugar se hiciera constar representen a $v$. ex. El pleno acordó negarse a modificarlo, puesto que Barcelona tenía el derecho de aconsejar y de protestar ante el virrey ${ }^{30}$. Pocos días después, el virrey detuvo a dos jurados del Consellpor algunas propuestas atrevidas, como la de que los consellers y los jurados de la ciudad vistiesen la gramalla ${ }^{31}$ negra, para mostrar el luto, puesto que se habían violado las leyes de la patria ${ }^{32}$.

27 Florensa I Soler, N., El Consell de Cent..., págs. 453-458.

28 ELLIOTT, J.H., La rebelión de los catalanes (1598-1640), Madrid, 1977 (1. a edición, en inglés, 1963), págs. 344-370.

29 Arxiu Historic Ciutat Barcelona (en adelante AHCB), Deliberacions, 1640, cartas s.f. adjuntadas al folio 303.

30 AHCB, Deliberacions, 1640, fs. 107-107v.

31 La gramalla era la indumentaria consular de los consellers de Barcelona. Era de color púrpura para simbolizar que guardaban el bien común y el de su patria y que para conservarlo darian la sangre de sus venas y perderian la vida. BRUNIQUER, Esteve Gilabert, Relació sumària de l'antiga fundació ..., Barcelona, 1630, pág. 37.

32. Assarino, Luca, Revolutioni di Catalogna, Bologna, 1648, pág. 67. BC, FB-152. 
Posteriormente, fue detenido el diputado militar por la oposición a los procedimientos que se utilizaban para los alojamientos del ejército. Con estos actos, se inició el ambiente favorable para la conspiración, la revuelta y la revolución ${ }^{33}$.

Desde el mes de marzo Barcelona empezó a fortificarse como no lo habia hecho hasta entonces. El aumento de los gastos municipales en concepto de fortificaciones era evidente, pues a mediados de marzo ya se habian gastado 5.000 libras $y$, como las obras iban en aumento, se destinaron 1.000 más al mismo fin ${ }^{34}$. Hay que añadir al clima pre-bélico las actividades propagandísticas realizadas en febrero y marzo, contrarias a los alojamientos y a favor de la rebelión ${ }^{35}$, y los primeros contactos y las negociaciones con Francia ${ }^{36}$, que son un motivo más para anticipar ${ }^{37}$ la cronologia clásica sobre la revuelta catalana, se iniciaban poco antes del 7 de junio de 1640.

De forma metódica, fue desarrollándose un engranaje imparable que condujo irremisiblemente a la guerra: prohibición de entrar en Madrid a los embajadores enviados por la Generalitat y el Consell de Cent ${ }^{38}$; falta de resolución para castigar y atajar los excesos del ejército real; revueltas sucesivas en Barcelona ( 22 de mayo, 3 de junio y 7 de junio - Corpus de Sang-). En la jornada del Corpus murió el virrey, el conde de Santa Coloma. Si bien inicialmente, los motines fueron sofocados por los consellers, posteriormente éstos no impidieron los tumultos: la finalidad era mostrar el descontento y los agravios que sentían los catalanes. La Generalitat

33 Serra, Eva; Torres I Sans, Xavier; Puigvert, Joaquim M.; Olivares, Jordi; Alcoberro, Agusti; Vidal, Jordi; Sales, Núria; TorRas । Ribé, Josep M.; AlbaredA, Joaquim, La revolució catalana de 1640, Barcelona, 1991. Además, Elliott, J.H.; Villari, R.; Hespanha, A.M.; Anatra, B. y otros, 1640: La Monarquía hispánica en crisis, Barcelona, 1991.

34 Florensa I SOLER, Núria, "Les fortificacions de Barcelona, motiu de desafiament a Felip IV de Castella": El municipi de Barcelona i els combats pel govern de la ciutat, (Coord. Joan RocA I ALBERT) Barcelona, 1997, págs. 41-48.

35 FloRensa I SOlER, Núria, "La ciutat de Barcelona i la Reial Audiència contra Felip IV de Castella: Alo pes de las paraules", XVII Congrés a História de la Corona d'Aragó, El món urbà a la Corona d'Aragó .... Barcelona-Lleida, 2.000 (en preparació); El Consell de Cent..., págs. 567578.

36 Florensa i Soler, N., El Consell de Cent..., págs. 536-540.

Pujol 1 CAMPS, Celestino, De los muchos sucesos dignos de memoria que han ocurrido en Barcelona y otros lugares de Cataluña, Crónica escrita entre los años 1626 a 1660 por PARETS, Miquel (Memorial Histórico Español, vol. XX-XXV, 6 vols., Madrid, 1888-91). Hay que destacar que PUJOL I CAMPS aportó con reservas (tomo II, Nota preliminar, págs. VI-XII) un documento (núm. 335, Apéndice $X$. Tomo XXI, págs. 416-419) donde se referencia que los primeros contactos entre los catalanes y los franceses se hicieron a mediados de marzo de 1640. Ferran SoldEVILA, (Història de Catalunya, 3 vols, Barcelona, 1962, vol. 3, págs. 1018-1020) y José Sanabre (La acción de Francia..., págs. 92-93) consideraron el documento apócrifo y se perpetuó esta valoración. Hay que tener en cuenta que los borradores o las minutas son la base de los documentos definitivos. 
envió diversas notificaciones para informarse de la situación a diferentes localidades catalanas y pidió al Consell de Cent que las acompañase con una carta suya; y así se hizo ${ }^{39}$.

Mientras se dilataban las investigaciones del día del Corpus, la Corte sospechaba - y no sin motivo- que los consellers no tenian intención de castigar a los culpables, pues algunos barceloneses que habian participado en el motín paseaban libremente por Barcelona, como era el caso de Josep Novis, alférez de las compañias de la ciudad y uno de los responsables de los disturbios en aquella jornada; y el de Rafael Goday, jefe de los amotinados del Prat que quemó las casas del Dr. Puig, Massó y Mir - jueces de la Real Audiencia - y que "pasea públicamente acompañado de algunos fadrines por la ciudad, y entra muy de ordinario en las casas de la ciudad dende le hazen fiestas y cumplimientos los conselleres y officiales della” ${ }^{40}$.

Al mismo tiempo, el vacío de poder de la ciudad se hizo evidente, pues la autoridad, tras la muerte del virrey había pasado al gobernador, que como oficial real lo sustituía, pero éste había desaparecido de Barcelona, cosa que los consellers comunicaron al rey para justificar su autoridad absoluta en la ciudad. Sin embargo, el Consell de Cent tampoco podía consentir el desorden existente. Así, la primera medida adoptada fue la de alejar a aquella población de provocadores, motivo por el que organizaron un ejército para mandarlo en socorro de Perpiñán, que estaba ocupada por las tropas reales. Las autoridades catalanas no podian precipitadamente iniciar una guerra contra un imperio, por lo que recondujeron sus acciones. Así, al cabo de unos días, licenciaron a aquel ejército improvisado que habian conseguido alejar de Barcelona. Pero, en cambio, los consellers conservarian y pagarian a un pequeño grupo armado, de unos 46 soldados experimentados, procurando reclutar más para tenerlos a su servicio en caso de necesidad ${ }^{41}$.

La ruptura con Felipe IV era inevitable, ya que consellers y diputats habían tomado la determinación de que todos los acuerdos con el rey habian de incluir la retirada de su ejército de Cataluña. Poco a poco, el Consell de

38 AHCB, Deliberacions, 1640, s.f. insertado en el f. 177. Sanabre, J., La acción de Francia..., pág. 70, juzgó el hecho como de gran incompetencia politica por parte de los ministros reales.

39 AHCB, Deliberacions, 1640, f. $216 \mathrm{~V}$.

40 Arxiu Corona d'Arago (ACA), Consell d'Aragó, leg. 286, núm. 83. Copia de la carta del Dr. Felip Vinyes - -juez de la Real Audiencia- a P. Villanueva, II de junio de 1640. AHCB, Dietari del Antich Consell Barceloni, Tom. XII, págs. 752, 757, 766. Assarino, L., Revolutioni di Catalogna.... págs. 127-128.

${ }_{41} \mathrm{AHCB}$, Lletres Closes, 1640 , fs. 154v.-155, 182-182v. 
Cent fue concentrando atribuciones y ejecutando decisiones: requisa de caballos reales; recogida, demanda y difusión de informaciones militares; compra y distribución de armas y municiones; compra y almacenamiento de trigo (de Francia) y otros productos; embargo de las Atarazanas reales y de la Batllía General ${ }^{42}$; reclutamiento de soldados; revisión y aceptación de los acuerdos de los diputats; soporte económico de la ciudad a la guerra (empréstitos, creación de censales municipales, garantías a los censales de la Generalitat ${ }^{43} \ldots$ ); etc.

Inicialmente, la táctica militar del Principado resultó inoperante. Diversos mandos actuaban sin suficiente coordinación: la Generalitat, el Consell de Cent, las tropas auxiliares francesas - llegadas para socorrer a los catalanes-, junto con las demás poblaciones y los militares. A medida que el ejército real dirigido por el marqués de los Vélez avanzaba sin grandes dificultades, las tropas catalanas se replegaban hacia Barcelona, obligando a las autoridades a modificar y concentrar el mando militar. Así, se hizo un llamamiento a toda la población comprendida entre los 15 y los 65 años que no estuviera movilizada para que se incorporara, bajo pena de confiscación de bienes ${ }^{44}$. Del mismo modo, para agilizar la defensa de Barcelona y de toda Cataluña, se constituyó una Junta de Guerra muy reducida y con amplios poderes. La Junta era un gobierno tripartito: el diputado militar Francesc de Tamarit, el conseller en cap Joan Pere Fontanella y el ingeniero militar francés Du Plessis-Besançon ${ }^{45}$.

Al mismo tiempo, en la Generalitat se formaba una Junta militar en cuya elección y nombramiento intervinieron los consellers ${ }^{46}$. La Diputación del General habia cedido autoridad y poder al Consell de Cent al concederle una participación muy amplia. De esta manera conseguía un mando unificado y eficaz para luchar en la guerra.

Finalmente, el 26 de enero de 1641 -batalla de Montjuïc - se enfrentaron en Barcelona las tropas reales del marqués de los Vélez y las franco-catalanas. Los catalanes ganaron la batalla, pero el ejército de Felipe IV tenía en su poder Perpiñán, Tarragona y otras localidades, por lo que prosiguió la guerra.

42 AHCB, Deliberacions, 1640, fs. 122, 242v.-244, 313, 335v, 337, 340v., y Lletres Closes, 1640 , fs. 33-33v., 37v. $-38,142-143 v ., 169 v .-170,189 v .-190 v$.

AHCB, Deliberacions, 1640, f. 71v.-73v.

44 AHCB, Deliberacions, 1641 , is. $77 \mathrm{~V} .-78$

AHCB, Deliberacions, 1640, f. 85.

AHCB, Lletres Closes, 1641, fs. 176v.-177, 23 de enero de 1641. 
Al tiempo que asumia un papel protagonista en el esfuerzo bélico, el Consell de Cent se convirtió en el precursor de las campañas publicísticas a favor de la guerra contra Castilla, debido a la fecha tan temprana de inicio y por hacerse cargo de la financiación.

La utilización y la difusión de las obras impresas propagandísticas era común en toda Europa ${ }^{47}$. La "guerra de tinta" fue la guerra intelectual y psicológica que mantuvieron Cataluña y Castilla para autojustificarse. Los dos bandos utilizaron la pluma como un elemento decisivo para incitar a sus partidarios y procurar que tomaran una postura favorable a sus intereses ${ }^{48}$. En la mentalidad cultural de la época era común publicar escritos en defensa de cada una de las partes del litigio bélico; por ejemplo, en el año 1635 al iniciarse formalmente la guerra entre España y Francia ${ }^{49}$.

Los elementos de la literatura política de la "guerra de tinta" fueron diversos desde la visión catalana. De manera resumida y sistemática giraron alrededor de varios postulados. Destacaron el providencialismo histórico catalán, resaltaron los textos alusivos a la predestinación divina de los catalanes y buscaron las soluciones de los conflictos presentes en los textos evangélicos ${ }^{50}$, por ejemplo haciendo comparaciones bíblicas: los israelitas y David en nombre de Dios, representando a los catalanes, contra el gigante Goliat por analogía con la arrogancia de los castellanos ${ }^{51}$.

También utilizaron otros simbolismos: el conde de Olivares y el protonotario Villanueva fueron tratados como "Nerones" crueles 52; Troya se comparó con Cataluña ${ }^{53}$; se hicieron diversas fábulas con animales (Castilla como león, Luis XIII de Francia como gallo y Olivares como burro ${ }^{54}$ );

47 Kamen, Henry, El siglo de hierro. Cambio social en Europa, 1550-1660. Madrid, 1982, págs. 322-337. Es indispensable consultar los trabajos pioneros de Garcia CARCEL, Ricardo; NiCOLAU BAQUER, Helena, "Castella contra Catalunya: La batalla lingüística al segle XVIl»: L'Avenç, núm. 22, Barcelona, 1979, págs. 42-47; Garcia CARCEL, R., "Enfrentamiento ideológico": Historia 16, núm. 48, Madrid, 1980, págs. 55-66; y del mismo autor, Historia de Cataluña. Siglos XVI-xvII, 2 vols., Barcelona, 1985, vol. 1, págs. 137-187. BuRgos RINCON, F.J.; PENA DiAZ, M., "Aportaciones sobre el enfrentamiento ideológico entre Castilla y Cataluña en el siglo XVII. (La publicística catalana)": Actes Primer Congrés d Història Moderna de Catalunya, vol. II, Barcelona, 1984, págs. 557-567.

48 Quizás en algunos textos podía desarrollarse un antagonismo superior al que existía, pero no obstante la rebelión catalana terminó en guerra contra la Monarquía. Cfr. BelengueP. CEBRIA, Ernest, "La monarquía hispánica vista desde la Corona de Aragón": Estudis, 20, 1994, págs. 57-82, en concreto págs. $60-61$.

49 BC, FB-26, FB-28, FB-32.

5o EliAS DE TEJADA, Francisco, Las doctrinas políticas en la Cataluña medieval, Barcelona, 1950, pág. 129.

51 BC, FB-6215.

52 BC, FB-6135. AHCB, Carta que ha enviada... Perpinyà (1641).

b3 $\mathrm{BC}, \mathrm{FB}-6215, \mathrm{BC}, \mathrm{FB}-7553$.

54 BC, FB-6191. 
La ciudad de Barcelona en la guerra contra Felipe IV: el Consell de Cent...

y se utilizó el sufrimiento de los indígenas de América como ejemplo contra la tiranía de Olivares ${ }^{55}$. En diversas ocasiones atacaron los abusos del gobierno de Olivares, del protonotario y de los ministros reales, considerados todos unos traidores a la nación catalana. Al mismo tiempo excusaron la rebelión popular y elogiaron la defensa de la tierra que hacian los catalanes ${ }^{56}$.

No se olvidaron del aspecto religioso, ya que invocaron a diversos santos para que les ayudaran, mientras los catalanes eran presentados como defensores de la Iglesia. En efecto, la guerra contra Felipe IV también se enfocó como una lucha religiosa: "mueran los luteranos" ${ }^{57}$. En diversos escritos pretendieron justificar a los consellers, al Consell de Cent y a los diputats como garantía y defensores del orden y de las leyes ${ }^{58}$. Reiterativamente denunciaron los excesos de los soldados: sus saqueos y sacrilegios. Se atribuyó el descrédito de los catalanes en la campaña de Salses a la envidia de los castellanos. En diversas ocasiones denunciaron los alojamientos abusivos del ejército real, superiores a las posibilidades del país. En algunos textos destacaban la incapacidad del virrey Santa Coloma. Los escritos, finalmente, rechazaban la traición a Cataluña y exaltaban el valor por defenderla ${ }^{59}$.

Con toda la publicística catalana estuvo vinculado el Consell de Cent, dando su apoyo y costeando algunas de las publicaciones.

La producción escrita adquirió diversas modalidades: la sátira política, el panfleto, el libelo, el pasquín ..., desde papeles sueltos y opúsculos a libros editados por las instituciones.

Fue en Barcelona donde se inició: la primera noticia escrita que conocemos es un papel suelto que se encontró en la Sala del Consell de Cent el 19 de febrero de 1640 , domingo de Carnaval ${ }^{60}$. Al día siguiente aparecieron diversas copias en las calles. Eran unos papeles estampados firmados con el pseudónimo "Verdader Àngel de Llum" (Verdadero Ángel de Luz). La esencia del escrito tenía cuatro ideas básicas: el peligro que

\footnotetext{
55 Marti i Viladamor, Francesc, Cataluña en Francia..., 1641, págs. 42-44. Elliott, John H., El viejo mundo y el nuevo (1492-1650), Madrid, 1972, pág. 120.

$56 \mathrm{BC}, \mathrm{FB}-6135$.

$57 \mathrm{BC}$, FB-6135.

58 BC, FB-6135. AHCB, Carta que ha enviada ..., Perpinyà, 1641.

59 AHCB, Clari de veritats..., 1641.

60 BC, FB-6138, "Verdader Ȧngel de la Llum». Consideramos que los papeles sueltos se han de tener en cuenta para periodizar el enfrentamiento ideológico entre Cataluña y Castilla. Por lo tanto, avanzamos la periodización propuesta por Garcia CARCEL, R.; Nicolau Baquer, H., "Cas tella contra Catalunya...", y Garcia CARCEL, R., Historia de Cataluña..., vol. 1, pág. 139
} 
sufrian España y Cataluña; la falta de obligatoriedad del juramento dado por los catalanes, tal y como lo había afirmado una Junta de Teólogos (a excepción de uno solo); el gran esfuerzo material y físico de los catalanes en la guerra del Rosellón (12.030 muertos); y finalmente la referencia a Francia y los franceses ${ }^{61}$.

El virrey Santa Coloma mandó un ejemplar al rey, que le ordenó «severa y efectiva demonstración" por ser alta traición, "crimen de lesa Magestad» ${ }^{62}$. Los oficiales reales quisieron descubrir y castigar al autor, investigando a los impresores de Barcelona, pero no obtuvieron resultados ${ }^{63}$. Gracias a la vanidad del autor, que reveló su identidad en respuesta al posterior cuestionamiento de su autoría, hemos podido reconstruir la historia. El papel suelto fue escrito por Francesc Martí i Viladamor, un intelectual ingenioso, culto y refinado, cuyas actividades se diversificaban entre la abogacía, la política y la escritura. Su pluma erudita se puso al servicio de la rebelión catalana y por ello introdujo en el Consell de Cent su escrito, que sirvió de espoleta para presentar la moción de que los consellers se vistiesen de duelo como una demostración pública de que se habian conculcado las Constituciones de Cataluña. La propuesta se inspiraba en otra semejante del año 1416, en una situación análoga de conflicto con el rey Fernando I, que se negaba a pagar el impuesto de la carne a Barcelona y finalmente lo abonó.

Los papeles sueltos fueron impresos muchos días antes del 19 de febrero y, para más seguridad del autor, fueron remitidos a un confidente de Madrid, desde donde se enviaron a los consellers y al Consell de Cent. Es de suponer que, por prudencia, los magistrados no los hicieron públicos en el pleno, y por ello Martí con la ayuda de sus aliados introdujeron tres copias directamente en la sala municipal ${ }^{64}$.

El 26 de febrero, Francesc Martí escribió una carta, en la que optó por fingirse castellano a fin de conseguir sus propósitos ${ }^{65}$. En ella advertía al público contra los ministros "alucinados», hacia una apología en defensa de Barcelona (que habia sido atacada falsamente) y de los catalanes, y concluia con una retórica moralista sobre los pecados públicos que desencadenaban la ira de Dios ${ }^{66}$. En cualquier caso, como proseguían las investigacio-

\footnotetext{
BC, FB-6138.

62 Marti i VILAdamor, Francesc, Delirios de la passión en la muerte de la Embidia, Barcelona,

63 Marti I Villadamor, F., Delirios de la passión .... pág. 35.

64 Marti I Viladamor, F., Delirios de la passión .... pág. 50.

65 Marti i Viladamor, F., Avisos del Castellano fingido..., Barcelona, 1641.

66 Marti i Viladamor, F., Avisos del Castellano ..., Delirios de la passión..., págs. 43-47.
} 1641 , pág. 36 . 
nes para descubrir el Ȧngel de Llum, el autor retuvo el escrito. Pero el 19 de marzo de 1640, Martí se decidió a difundirlo tras la detención del diputat militar Francesc Tamarit ${ }^{67}$.

Por lo que hemos expuesto, puede afirmarse que ya durante los meses de febrero y marzo de 1640, existía un cenáculo político-literario en Barcelona organizado contra la Monarquía de Felipe IV. La articulación y la plasmación de sus deseos sólo fue cuestión de tiempo. También hay que resaltar que las fechas coinciden con los contactos catalano-franceses y con los gastos de fortificaciones de Barcelona, con lo que evidencian la necesidad de adelantar la periodización de la Guerra de Separación.

Para concluir con éstos papeles sueltos, precursores de la guerra, hay que destacar el fechado el 19 de junio de 1640, firmado con el pseudónimo "Lo Capità General del exèrsit Christià" («El Capitán General del ejército cristiano"). El escrito se difundió por Barcelona y fue entregado al Consell de Cent, donde se leyó. Se recordaba a las autoridades las responsabilidades de su cargo y se les incitaba para que hicieran lo mismo que habían hecho siglos antes sus predecesores con el rey Juan II (1458-1479), es decir se invocaba el acuerdo establecido con aquel monarca , prohibiéndole entrar en Cataluña sin autorización, imposición que fue una victoria del constitucionalismo catalán contra el autoritarismo monárquico. El paralelismo entre el siglo $x V$ y el siglo $X V I I$ servía de base para analizar y proyectar las situaciones futuras. Sobre la identidad del posible autor del conocido y comentado escrito, no se ha podido llegar a pruebas concluyentes. Pero nuestros estudios nos han llevado a considerar que la autoría de "Lo Capità General..." no es obra de una sola persona, sino que refleja una ideología compartida por aquellos que seguían la línea política de oposición a Castilla. En cualquier caso, también consideramos que el personaje que firma y que se autodenomina Capità General es Josep de Margarit i de Biure ${ }^{68}$. Este noble fue un miembro activo del partido pro-francés, destacó como gran militar y los franceses lo nombraron gobernador de Cataluña, exiliándose al finalizar la guerra a Francia, donde fue mariscal.

De manera oficial la "guerra de tinta" se inició el 17 de setiembre de 1640, fecha en que el Consell de Cent decidió escribir al rey y presentar la queja contra las personas del conde de Olivares y del protonotario Villanueva. Los consellers acordaron izar las banderas de la ciudad y pedir a

\footnotetext{
67 Marti i Viladamor, F., Delirios de la passión ..., págs. 46-50.

68 Por lo tanto, en esta identificación coincidimos con la que también hizo Eulogio ZuDAIRE Huarte (El Conde-Duque y Cataluña, Madrid, 1964, pág. 371), que consideró a Josep de Margarit i de Biure el autor del famoso escrito.
} 
los diputats que hicieran lo mismo. Además se agilizó la impresión del memorial que se estaba realizando a cargo del Consell de Cent. Dicho memorial era la obra Proclamación católica, escrita por el eclesiástico Gaspar Sala Berart, de la orden de San Agustín, directamente por encargo de los consellers. La impresión de memoriales financiados por el Consell de Cent fue frecuente a partir de entonces ${ }^{69}$.

Para finalizar hay que destacar que en 1640 las clases dirigentes catalanas recogieron el descontento general y lo encauzaron. Con el apoyo popular se negaron a ceder y a olvidar los derechos y leyes de Cataluña. Esta fue la base jurídica del pensamiento político de los rebeldes a la Monarquía hispánica y el argumento fundamental, al que se añadieron muchos otros. La resistencia se transformó en una guerra abierta entre Cataluña y su rey. La confluencia de intereses entre las clases privilegiadas - aristocracia y burguesia--, las populares -urbanas y rurales-, y una gran parte del estamento eclesiástico, conllevó el triunfo de la revolución y, como consecuencia, la guerra contra Castilla, que simbolizaba el absolutismo de Felipe IV y de sus ministros, en especial el conde duque de Olivares y el protonotario Villanueva. El Consell de Cent sufrió constantes presiones económicas, diversos agravios y la conculcación de algunas de las constituciones municipales, por lo que participó activamente en la confrontación contra Felipe IV. Barcelona se convirtió en la base esencial de la guerra: contribución económica, reclutamiento de soldados, compra y distribución de armas para otras localidades, centro de información y decisión militar, etc. Los consellers y los diputats formaron un bloque contra la Corona: esta unión fue esencial para el éxito de la rebelión y la fase inicial de la guerra ${ }^{70}$.

69 Flchensa I SOler, N., El Consell de Cent..., págs. 575-578.

to AHCB, Reg. Lletres Reials, 1639, VII-6, fs. 22-22v. 